\title{
A Bifunctional Photosensitizer for Enhanced Fractional Photodynamic Therapy: Singlet Oxygen Generation in the Presence and Absence of Light
}

\author{
Ilke Simsek Turan, Deniz Yildiz, Abdurrahman Turksoy, Gurcan Gunaydin, and \\ Engin U. Akkaya*
}

\begin{abstract}
The photosensitized generation of singlet oxygen within tumor tissues during photodynamic therapy (PDT) is self-limiting, as the already low oxygen concentrations within tumors is further diminished during the process. In certain applications, to minimize photoinduced hypoxia the light is introduced intermittently (fractional PDT) to allow time for the replenishment of cellular oxygen. This condition extends the time required for effective therapy. Herein, we demonstrated that a photosensitizer with an additional 2-pyridone module for trapping singlet oxygen would be useful in fractional PDT. Thus, in the light cycle, the endoperoxide of 2-pyridone is generated along with singlet oxygen. In the dark cycle, the endoperoxide undergoes thermal cycloreversion to produce singlet oxygen, regenerating the 2-pyridone module. As a result, the photodynamic process can continue in the dark as well as in the light cycles. Cell-culture studies validated this working principle in vitro.
\end{abstract}

P hotodynamic therapy has, for some time, been considered a promising method for the treatment of various cancers. ${ }^{[1]}$ The therapeutic procedure involves the photosensitized generation in tumor tissues of singlet oxygen, which is cytotoxic and has a short lifetime, increasing the chances of selective action. There are other aspects of photodynamic therapy (PDT) which makes it appear truly promising, such as an enhanced immune response following a PDT session. ${ }^{[2]}$ Nevertheless, clinical application of PDT seems to limited mostly to superficial lesions. ${ }^{[3]}$ One reason for the limited application of the method is the fact that PDT requires oxygen, but most tumors develop regions of severe hypoxia where photosensitized singlet oxygen generation would not be expected. ${ }^{[4]}$ More problematic is the fact that PDT itself, by

[*] Dr. I. S. Turan, Prof. Dr. E. U. Akkaya

UNAM-National Nanotechnology Research Center

Bilkent University

06800 Ankara (Turkey)

E-mail: eua@fen.bilkent.edu.tr

D. Yildiz, A. Turksoy, Prof. Dr. E. U. Akkaya

Department of Chemistry, Bilkent University

06800 Ankara (Turkey)

Dr. G. Gunaydin

Department of Basic Oncology, Hacettepe University 06100 Ankara (Turkey)

(2) Supporting information (including methods, experimental proce-

iD dures, and additional spectral data) and $\operatorname{ORCID(s)~from~the~}$ author(s) for this article are available on the WWW under http://dx. doi.org/10.1002/anie.201511345. rapidly using intracellular oxygen reserves, creates acute hypoxia. ${ }^{[5]}$ Many studies suggest that fractional (intermittent) delivery of light might be a better approach to PDT. ${ }^{[6]}$ Thus, between irradiation periods, time is allocated for the replenishment of intracellular oxygen.

Considering the fact that singlet oxygen is the ultimate cytotoxic agent required for effective PDT, we thought of using chemically generated singlet oxygen for the dark period of fractional PDT, where photosensitized generation is not possible. In fact, it would be highly interesting to combine a photosensitizer and a chemical source of singlet oxygen in a single molecule.

The endoperoxides of 2-pyridone and derivatives have been recognized as reliable chemical sources of singlet oxygen as they undergo clean (no side reactions) cycloreversion reactions to release singlet oxygen with very high yields. ${ }^{[7-9]}$ In fact, it has been already reported that singlet oxygen produced by the thermal decomposition of 2-pyridone endoperoxides lead to cell death by a process resembling apoptosis in cancer cell cultures. ${ }^{[10]}$ In addition, phthalocyanine $^{[11]}$ and porphyrin endoperoxide ${ }^{[12]}$ derivatives were reported where the endoperoxides are obtained by selfphotosensitization. Thus, it is evident that a rationally designed bifunctional photosensitizer/2-pyridone conjugate may be an optimal agent for a novel approach to fractional photodynamic therapy. 2,6-Dibromo (and iodo) distyryl BODIPY derivatives (BODIPY=boron-dipyrromethene) were shown ${ }^{[13-16]}$ to be promising long-wavelength sensitizers of molecular oxygen. In addition, the versatility of the chemistry of BODIPY derivatives has led to the employment of these molecules more and more frequently in the development of novel strategies towards the improvement of PDT. ${ }^{[17]}$

Based on these considerations, we designed a bifunctional compound to meet the requirements for enhanced fractional photodynamic therapy. The operation principle for the generation of singlet oxygen is shown in Figure 1. When excited at $\lambda=650 \mathrm{~nm}$, the upper dye molecule in the figure (Pyr 6) is expected to generate singlet oxygen, and some of it will be "stored" in the form of a 2-pyridone endoperoxide (EPO 7). When the irradiation is turned off, as it would be in fractional PDT (for the replenishment of intracellular oxygen), the 2-pyridone-endoperoxide (EPO 7) will undergo thermal cycloreversion producing singlet oxygen in the absence of light.

The syntheses of the target compounds are shown in Scheme 1. The key step is the functionalization of 2-pyridone with an arylaldehyde group. The aldehyde functionality 


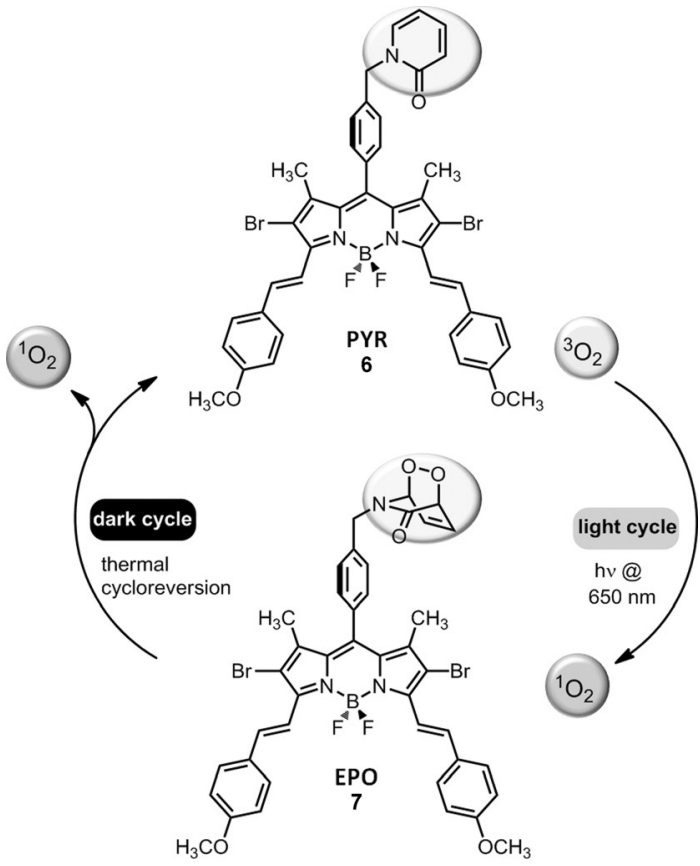

Figure 1. Singlet oxygen generation achieved first by irradiation of bifunctional compound 6 at $\lambda=650 \mathrm{~nm}$, and subsequently by thermal cycloreversion in the dark. The cycles can be repeated indefinitely.

provides easy access to BODIPY structures, and in this case we were able to obtain compound $\mathbf{4}$ in good yields. Bromination with $N$-bromosuccinimide (NBS) affords compound 5. In 5, the presence of the heavy bromine atoms facilitated intersystem crossing, which is essential for photosensitized singlet oxygen generation. Next, to shift the absorption maximum of the BODIPY chromophore to a region more relevant for PDT, compound $\mathbf{5}$ was reacted
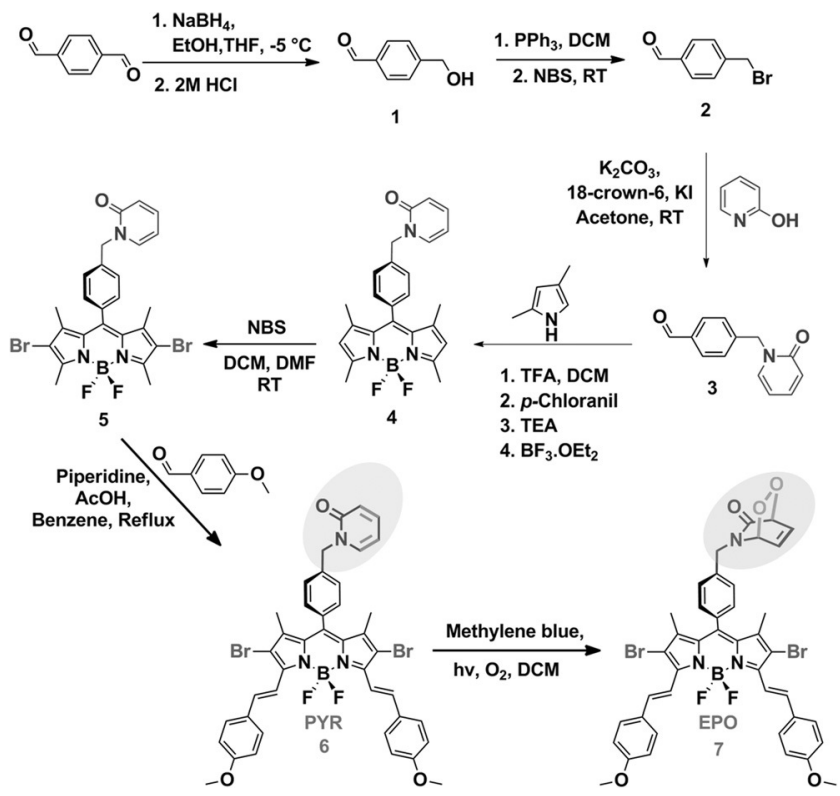

Scheme 1. Synthesis of the target pyridone (6) and endoperoxide (7) derivatives. $\mathrm{DCM}=$ dichloromethane; TFA = trifluoroacetic acid; TEA = triethylamine; $p$-chloroanil = tetrachloro- $p$-benzoquinone. with $p$-methoxybenzaldeyde to form compound 6 . The distyryl-BODIPY compound $\mathbf{7}$ was formed after irradiation of $\mathbf{6}$ in the presence of methylene blue. Compound $\mathbf{7}$ has an absorption maximum at $\lambda=667 \mathrm{~nm}$ at the red region of the visible spectrum, with an extinction coefficient of $74200 \mathrm{~cm}^{-1} \mathrm{M}^{-1}$.

We first set out to demonstrate the reversibility of the transformation between the pyridone (PYR 6) and the endoperoxide (EPO 7). Fortunately, the ${ }^{1} \mathrm{H}$ NMR spectra of the two compounds have well-resolved characteristic signals for both the PYR and EPO forms. Partial ${ }^{1} \mathrm{H}$ NMR data are shown in Figure 2. The triplet at $\delta=6.25 \mathrm{ppm}$ is attributable to a proton on the pyridone ring and the $\mathrm{AB}$ system between 4.6 and $4.9 \mathrm{ppm}$, an indicator of endoperoxide formation, is attributable to $\mathrm{N}-\mathrm{CH}_{2}$ protons. Spectrum A is the partial ${ }^{1} \mathrm{H}$ NMR spectrum (showing the $\delta=4.4-6.4 \mathrm{ppm}$ region) of compound $\mathbf{6}$, or the PYR form.
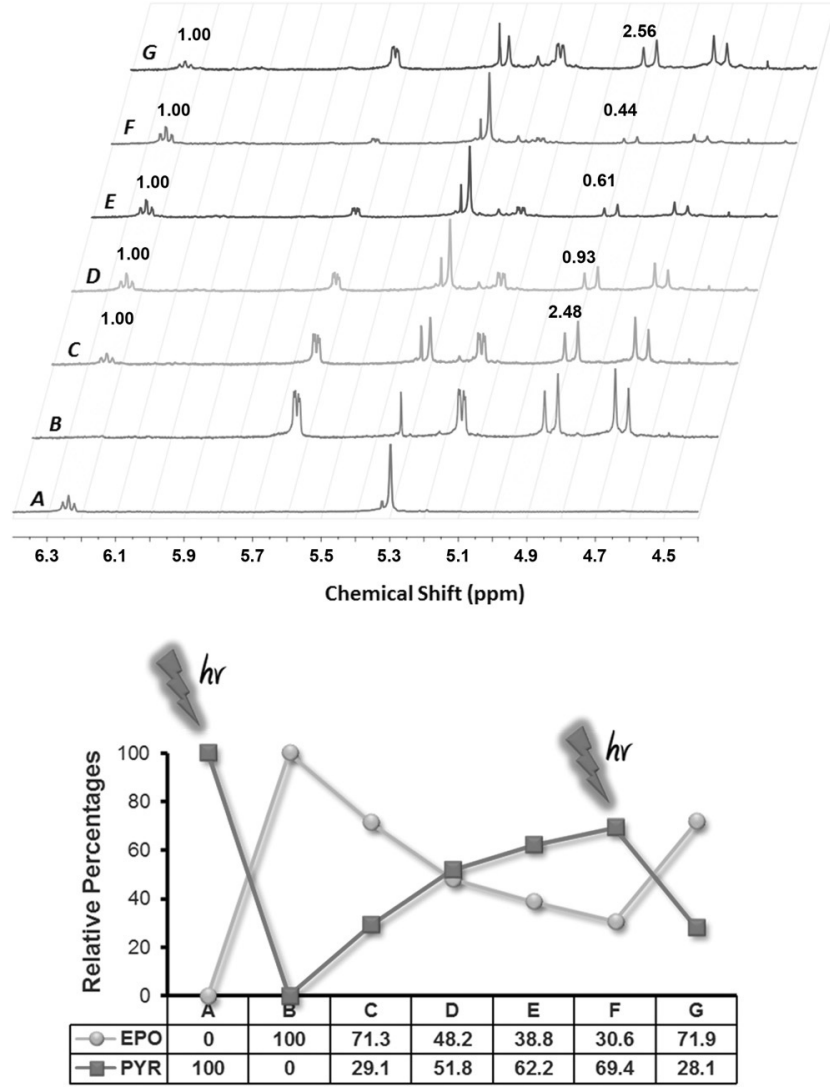

Figure 2. Top: Partial ${ }^{7} \mathrm{H}$ NMR spectra $\left(\mathrm{CDCl}_{3} ; 37^{\circ} \mathrm{C}\right)$ demonstrating the reversibility of the interconversion between compound 6 (PYR) and compound 7 (EPO). Spectrum A shows the partial NMR spectrum of the sample (PYR 6) recorded at 0 min. Spectrum $B$ is that of the sample after irradiation at $\lambda=650 \mathrm{~nm}$ for $15 \mathrm{~min}$ in the NMR tube, forming EPO 7 (a very weak stream of oxygen was bubbled through the sample throughout the experiment). The other spectra were recorded at $15 \mathrm{~min}$ intervals in the dark at $37^{\circ} \mathrm{C}$. Bottom: Relative percentages of 6 and 7 present during the conversion between the two forms. The conversion process was monitored by measuring the integrated peak areas for the characteristic NMR signals of each form. Relative percentages of both forms (corresponding to the upper NMR spectra) are given in the table under the plot. 
The ${ }^{1} \mathrm{H}$ NMR spectrum of EPO 7 in the same region is presented in Figure 2 (top) as the other reference spectrum (spectrum B). This spectrum is obtained by irradiation of compound 6. When the irradiation was stopped and the solution kept in the dark at $37^{\circ} \mathrm{C}$, the spectra gradually evolved from spectrum B to F. At that point, the NMR tube was irradiated again for a short time, which clearly regenerated unmistakable resonance signals for the endoperoxide (such as the AB system around $\delta=4.75 \mathrm{ppm}$ ). Thus, it is clear that interconversion between the two forms occurred as long as there was dissolved oxygen present during the irradiation.

The formation of singlet oxygen was further studied using the selective singlet-oxygen trap molecule 1,3-diphenylisobenzofuran (DPBF). Under irradiation with an LED array at $\lambda=650 \mathrm{~nm}$, halogenated distyryl-Bodipy sensitizes groundstate molecular oxygen to generate singlet oxygen. The trap molecule reacts with the singlet oxygen, resulting in a decrease in the absorbance of DPBF at $\lambda=416 \mathrm{~nm}$. As mentioned earlier, during this light cycle the molecule is transformed from the PYR form into the EPO form. When the irradiation at $\lambda=650 \mathrm{~nm}$ is switched off, the EPO form gradually cycloreverts to the PYR form, generating simultaneously singlet oxygen in the dark cycle. The results of this experiment and that of the control, which is the trap compound DPBF (in DMSO) subjected to the dark and light cycles, are shown in Figure 3.

The performance of the bifunctional photosensitizer was also studied in HeLa (human cervical cancer cell line) cell cultures. Our expectation was that EPO 7 would be a more effective cytotoxic agent compared to a simple photosensitizer in when employed in the dark-light cycle regime (as is done in fractional PDT). Since the apoptotic response is timedependent, a more fair comparison would be to compare the effects of PYR and EPO. Since both compounds had very limited water solubility, the non-ionic surfactant cremophor EL was used to deliver the agents within a micellar

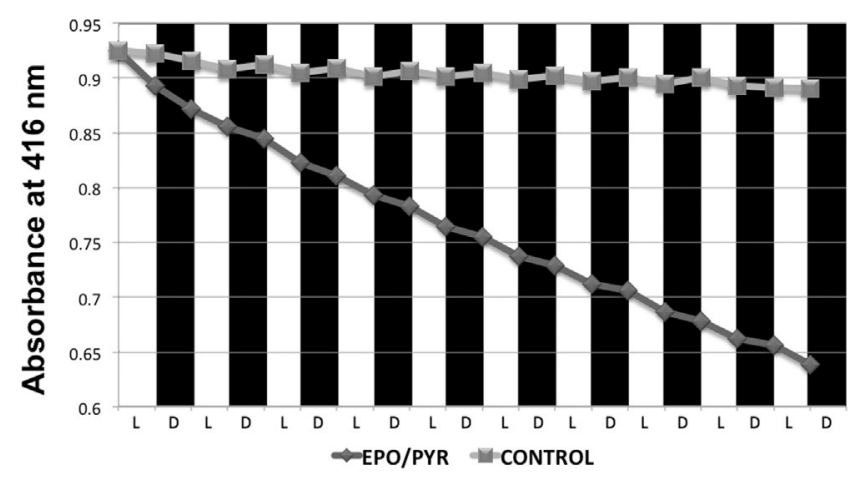

Figure 3. Decrease in the absorbance (at $\lambda=416 \mathrm{~nm}$ ) of the trap compound DPBF in the presence (blue line) and the absence (green line; i.e. trap compound DPBF alone) of the EPO/PYR agent $(6 / 7)$. The reaction was carried out at $37^{\circ} \mathrm{C}$ in DMSO. White bars correspond to the periods of irradiation ( $\mathrm{L}$, light cycles) which was carried out using a red LED array irradiating at $\lambda=650 \mathrm{~nm}$ for $30 \mathrm{~s}$. Black bars (D, dark cycles) correspond to the dark periods, where both solutions were kept in the dark for $30 \mathrm{~min}$. A gentle stream of oxygen was bubbled through the reaction and control samples. There is a slight decrease in the absorbance of the control in the light cycle as expected, but no significant change takes place in the dark. structure. Micelles were prepared following literature procedures. ${ }^{[17 \mathrm{c}]}$ The size distribution of the micelles was studied by using dynamic light scattering, which showed that the average size of the micelles carrying embedded $\mathbf{7}$ or $\mathbf{8}$ is about $50 \mathrm{~nm}$. HeLa cells were incubated with complete Dulbecco's modified Eagle's medium (DMEM) under environmental conditions of $37^{\circ} \mathrm{C}, 5 \% \mathrm{CO}_{2}$, and $60 \%$ humidity. Cells were exposed to varying concentrations of the compounds in cremophor EL micelles $(9 \mathrm{nM}-2.5 \mu \mathrm{M})$ and illuminated with a red light source $\left(\lambda=655 \mathrm{~nm}\right.$ LED array, $324 \mu \mathrm{molm}^{-2} \mathrm{~s}^{-1}$ photon flux) for $10 \mathrm{~min}$ in every one hour, which was repeated 24 times. Thus, the total illumination time was exactly $4 \mathrm{~h}$. This $24 \mathrm{~h}$ period of light-dark cycles was then followed by a $24 \mathrm{~h}$ incubation period in the dark (total $48 \mathrm{~h}$ ). The control group of cells were incubated in the dark for $48 \mathrm{~h}$ under identical environmental conditions. MTT assays were performed to assess cell viability and cytotoxicity (Figure 4). It

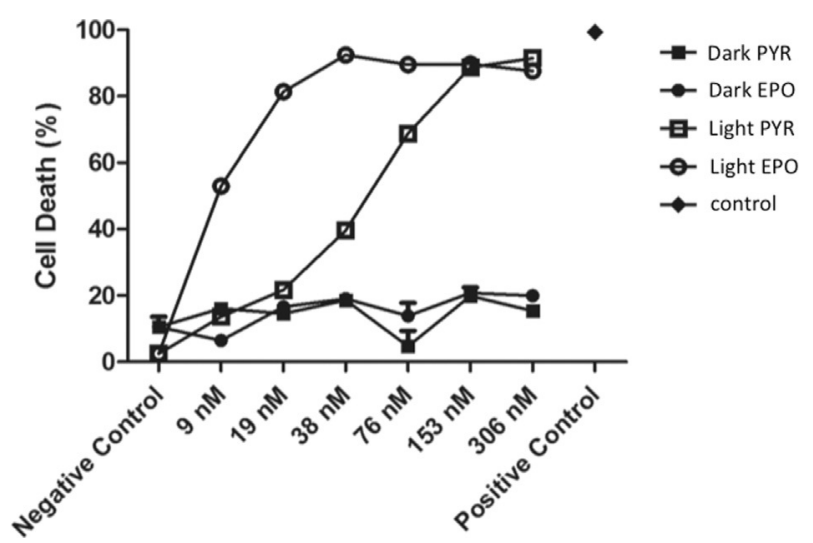

Figure 4. Cell viabilities as determined by MTT assays. Data labeled as "light" refers to results obtained when indicated concentrations of micelle-delivered agents PYR (6) and EPO (7) were exposed to cycles of light $(\lambda=655 \mathrm{~nm}, 10 \mathrm{~min})$ and dark $(50 \mathrm{~min})$ with a total of $4 \mathrm{~h}$ of light exposure, followed by $24 \mathrm{~h}$ of incubation in the dark. The label "dark" indicates compounds which had been incubated in the dark only for $48 \mathrm{~h}$.

was found that even low doses of compound 7 (EPO) results in a significant decrease of the cell viability. The $\mathrm{CC}_{50}$ values (50\% cytotoxic concentration) of the compounds both in the dark and after irradiation were estimated by fitting a model with nonlinear regression. The $\mathrm{CC}_{50}$ value of compound 7 (EPO) was found to be significantly less than that of 6 (PYR) after intermittent illumination of both (approximately $8.6 \mathrm{nM}$ versus $49.0 \mathrm{~nm}$ ). This result validates our design as it suggests that initial EPO cycloreversion results in a large difference in singlet oxygen generation when followed by the application of a light-dark cycle. Additionally, when considering the reported $\mathrm{CC}_{50}$ values, EPO 7 is, as expected, much more active as a photosensitizing cytotoxic agent compared to previously reported Bodipy-based long-wavelength photosensitizers which do not have reversible singlet-oxygen storage modules. ${ }^{[1 \mathrm{f}]}$

In this proof-of-principle study, we have prepared a bifunctional photosensitizer to improve fractional PDT. We demonstrated that continuous release of singlet oxygen from the 
photosensitizer can be achieved in both light and dark cycles, leading to significant differences in cytotoxic activity in cell culture studies compared to conventional PDT agents. We propose that when the system is applied in vivo, while the oxygen levels in the tumor tissues are replenished for the next round of photosensitized singlet oxygen generation, thermal cycloreversion will continue to produce singlet oxygen in dark, without consuming molecular oxygen. Considering the fact that tumor hypoxia and PDT-induced hypoxia are major problems hindering the broader applicability of PDT, we are confident that bifunctional PDT agents will have a promising future.

\section{Acknowledgements}

I.S.T. gratefully acknowledges support from TUBITAK in the form of a postdoctoral scholarship. A.T. is grateful to TUBITAK for a graduate student scholarship (2210-E).

Keywords: BODIPY $\cdot$ peroxides · photochemistry · photodynamic therapy $\cdot$ singlet oxygen

How to cite: Angew. Chem. Int. Ed. 2016, 55, 2875-2878 Angew. Chem. 2016, 128, 2925-2928

[1] a) R. Bonnett, Chem. Soc. Rev. 1995, 24, 19-33; b) J. P. Celli, B. Q. Spring, I. Rizvi, C. L. Evans, K. S. Samkoe, S. Verma, B. W. Pogue, T. Hasan, Chem. Rev. 2010, 110, 2795-2838; c) S. B. Brown, E. A. Brown, I. Walker, Lancet Oncol. 2004, 5, 497-508; d) T. J. Dougherty, J. E. Kaufman, A. Goldfarb, K. R. Weishaupt, D. Boyle, A. Mittleman, Cancer Res. 1978, 38, 2628-2635; e) D. E. Dolmans, D. Fukumura, R. K. Jain, Nat. Rev. Cancer 2003, 3, 380-387; f) A. Kamkaew, S. H. Lim, H. B. Lee, L. V. Kiew, L. Y. Chung, K. Burgess, Chem. Soc. Rev. 2013, 42, 77-88; g) T. Yogo, Y. Urano, Y. Ishitsuka, F. Maniwa, T. Nagano, J. Am. Chem. Soc. 2005, 127, 12162-12163.

[2] a) A. P. Castano, P. Mroz, M. R. Hamblin, Nat. Rev. Cancer 2006 6, 535-545; b) M. Korbelik, B. Stott, J. Sun, Br. J. Cancer 2007 , 97, 1381-1387; c) S. Gollnick, S. Evans, H. Baumann, B. Owczarczak, P. Maier, L. Vaughan, W. Wang, E. Unger, B. Henderson, Br. J. Cancer 2003, 88, 1772-1779.

[3] a) Z. Huang, Technol. Cancer Res. Treat. 2005, 4, 283-293, b) M. G. Bredell, E. Besic, C. Maake, H. Walt, J. Photochem. Photobiol. B 2010, 101, 185-190; c) N. C. Zeitouni, A. R. Oseroff, S. Shieh, Mol. Immunol. 2003, 39, 1133-1136.

[4] a) Y. Liu, Y. Liu, W. Bu, C. Cheng, C. Zuo, Q. Xiao, Y. Sun, D. Ni, C. Zhang, J. Liu, Angew. Chem. Int. Ed. 2015, 54, 8105-8109; Angew. Chem. 2015, 127, 8223-8227; b) J. Xu, S. Sun, Q. Li, Y. Yue, Y. Li, S. Shao, Analyst 2015, 140, 574-581; c) S. Wang, H. Liu, J. Mack, J. Tian, B. Zou, H. Lu, Z. Li, J. Jiang, Z. Shen, Chem. Commun. 2015, 13389-13392; d) K. Kiyose, K. Hanaoka, D. Oushiki, T. Nakamura, M. Kajimura, M. Suematsu, H. Nishimatsu, T. Yamane, T. Terai, Y. Hirata, J. Am. Chem. Soc. 2010, 132, 15846-15848; e) G. Zhang, G. M. Palmer, M. W. Dewhirst, C. L. Fraser, Nat. Mater. 2009, 8, 747-751; f) J. Pouysségur, F. Dayan, N. M. Mazure, Nature 2006, 441, $437-$ 443; g) X. Zheng, X. Wang, H. Mao, W. Wu, B. Liu, X. Jiang, Nat. Commun. 2015, 6, 5834; h) W. Gallagher, L. Allen, C. O'Shea, T. Kenna, M. Hall, A. Gorman, J. Killoran, D. O'Shea, Br. J. Cancer $\mathbf{2 0 0 5}, 92,1702-1710$; i) M. I. Koukourakis, A. Giatromanolaki, J.
Skarlatos, L. Corti, S. Blandamura, M. Piazza, K. C. Gatter, A. L. Harris, Cancer Res. 2001, 61, 1830-1832.

[5] a) C. Robertson, D. H. Evans, H. Abrahamse, J. Photochem. Photobiol. B 2009, 96, 1-8; b) I. Van Geel, H. Oppelaar, P. Rijken, H. Bernsen, N. Hagemeier, A. Van der Kogel, R. Hodgkiss, F. Stewart, Br. J. Cancer 1996, 73, 288-293; c) T. Sitnik, J. Hampton, B. Henderson, Br. J. Cancer 1998, 77, 13861394; d) T. M. Busch, S. M. Hahn, S. M. Evans, C. J. Koch, Cancer Res. 2000, 60, 2636-2642.

[6] a) Z. Xiao, S. Halls, D. Dickey, J. Tulip, R. B. Moore, Clin. Cancer Res. 2007, 13, 7496-7505; b) L. Yang, Q. Chen, Y. Wei, D. Xing, Lasers Surg. Med. 2010, 42, 671-679.

[7] a) J. Poully, J. Schermann, N. Nieuwjaer, F. Lecomte, G. Grégoire, C. Desfrançois, G. Garcia, L. Nahon, D. Nandi, L. Poisson, Phys. Chem. Chem. Phys. 2010, 12, 3566-3572; b) M. Matsumoto, M. Yamada, N. Watanabe, Chem. Commun. 2005, $483-485$.

[8] a) C. Wiegand, E. Herdtweck, T. Bach, Chem. Commun. 2012, 48, 10195-10197; b) J.-M. Aubry, C. Pierlot, J. Rigaudy, R. Schmidt, Acc. Chem. Res. 2003, 36, 668-675.

[9] S. Benz, S. Nötzli, J. S. Siegel, D. Eberli, H. J. Jessen, J. Med. Chem. 2013, 56, 10171-10182.

[10] a) K. Otsu, K. Sato, Y. Ikeda, H. Imai, Y. Nakagawa, Y. Ohba, J. Fujii, Biochem. J. 2005, 389, 197-206; b) K. Otsu, K. Sato, M. Sato, H. Ono, Y. Ohba, Y. Katagata, Cell Biol. Int. 2008, 32, 1380 - 1387; c) D. Posavec, M. Zabel, U. Bogner, G. Bernhardt, G. Knör, Org. Biomol. Chem. 2012, 10, $7062-7069$.

[11] T. Stuchinskaya, M. Moreno, M. J. Cook, D. R. Edwards, D. A. Russell, Photochem. Photobiol. Sci. 2011, 10, 822-831.

[12] a) W. Freyer, H. Stiel, M. Hild, K. Teuchner, D. Leupold, Photochem. Photobiol. 1997, 66, 596-604; b) C. Changtong, D. W. Carney, L. Luo, C. A. Zoto, J. L. Lombardi, R. E. Connors, J. Photochem. Photobiol. A 2013, 260, 9-13; c) M. A. Filatov, E. Heinrich, D. Busko, I. Z. Ilieva, K. Landfester, S. Baluschev, Phys. Chem. Chem. Phys. 2015, 17, 6501-6510.

[13] a) I. S. Turan, F. P. Cakmak, D. C. Yildirim, R. Cetin-Atalay, E. U. Akkaya, Chem. Eur. J. 2014, 20, 16088-16092; b) S. H. Lim, C. Thivierge, P. Nowak-Sliwinska, J. Han, H. van den Bergh, G. Wagnieres, K. Burgess, H. B. Lee, J. Med. Chem. 2010, 53, $2865-2874$; c) S. G. Awuah, J. Polreis, V. Biradar, Y. You, Org. Lett. 2011, 13, $3884-3887$.

[14] A. Loudet, K. Burgess, Chem. Rev. 2007, 107, 4891-4932.

[15] a) S. G. Awuah, Y. You, $R S C A d v$. 2012, 2, 11169-11183; b) W. Wu, Y. Geng, W. Fan, Z. Li, L. Zhan, X. Wu, J. Zheng, J. Zhao, M. Wu, RSC $A d v$. 2014, 4, 51349-51352; c) A. Kamkaew, K. Burgess, J. Med. Chem. 2013, 56, 7608-7614.

[16] a) S. Ozlem, E. U. Akkaya, J. Am. Chem. Soc. 2008, 130, 48-49; b) S. Erbas, A. Gorgulu, M. Kocakusakogullari, E. U. Akkaya, Chem. Commun. 2009, 4956-4958; c) G. Ulrich, R. Ziessel, A. Harriman, Angew. Chem. Int. Ed. 2008, 47, 1184-1201; Angew. Chem. 2008, 120, 1202-1219.

[17] a) S. Kolemen, M. Işık, G. M. Kim, D. Kim, H. Geng, M. Buyuktemiz, T. Karatas, X. F. Zhang, Y. Dede, J. Yoon, Angew. Chem. Int. Ed. 2015, 54, 5340-3344; Angew. Chem. 2015, 127, $5430-5434$; b) S. Erbas-Cakmak, E. U. Akkaya, Angew. Chem. Int. Ed. 2013, 52,11364-11368; Angew. Chem. 2013, 125, 1157411578 ; c) Y. Cakmak, S. Kolemen, S. Duman, Y. Dede, Y. Dolen, B. Kilic, Z. Kostereli, L. T. Yildirim, A. L. Dogan, D. Guc, Angew. Chem. Int. Ed. 2011, 50, 11937-11941; Angew. Chem. 2011, 123, 12143 -12147; d) S. G. Awuah, S. K. Das, F. D'Souza, Y. You, Chem. Asian J. 2013, 8, 3123-3132; e) J. F. Lovell, T. W. Liu, J. Chen, G. Zheng, Chem. Rev. 2010, 110, 2839-2857.

Received: December 7, 2015

Published online: January 22, 2016 